\title{
Roles of quaternary structure and cysteine residues in the activity of human serine racemase
}

Wei Wang ${ }^{1,2}$ and Steven W Barger ${ }^{1,2,3^{*}}$

\begin{abstract}
Background: D-serine is an important coagonist at the NR1 subunit of the NMDA receptor class of glutamate receptors. It is chiefly synthesized in the CNS by serine racemase (SR). Regulation of SR activity is still poorly understood. As step toward developing reagents and methods for investigating SR in vitro, we analyzed structurefunction relationships of a recombinant enzyme of human sequence.

Results: Michaelis-Menten kinetic analysis indicated a $K_{M}$ value of $14 \mathrm{mM}$ and $V_{\max }$ value of $3.66 \mu \mathrm{mol} \cdot \mathrm{mg}^{-1} \cdot \mathrm{hr}^{-1}$ when L-serine was used as a substrate for purified SR. Gel-filtration chromatography and protein cross-linking experiments revealed that dimer is the major oligomeric form of recombinant SR in aqueous solution, though the proportions of monomer, tetramer, and larger aggregates differed somewhat with the specific buffer used. These buffers also altered activity in a manner correlating with the relative abundance of dimer. Activity assays showed that the dimeric gel-filtration fraction held the highest activity. Chemical reduction with DTT increased the activity of SR by elevating $V_{\text {maxi }}$ cystamine, a reagent that blocks sulfhydryl groups, abolished SR activity. Gel-filtration chromatography and western blot analysis indicated that DTT enhanced the recovery of noncovalent SR dimer.

Conclusions: These data suggest that SR is most active as a noncovalent dimer containing one or more free sulfhydryls in the enzyme's active center or a modulatory site. Buffer composition and reduction/oxidation status during preparation can dramatically impact interpretations of SR activity. These findings also highlight the possibility that SR is sensitive to oxidative stress in vivo.
\end{abstract}

\section{Background}

When substantial levels of endogenous D-serine in the mammalian brain were discovered by Hashimoto et al. [1], the source of this unusual amino acid became a critical question. This intrigue was settled when Wolosker et al. [2] cloned the full-length mouse serine racemase (SR) gene and purified the enzyme from rat brain. These discoveries helped to legitimize D-serine as an endogenous signaling molecule. Colocalization of D-serine with NMDA receptor (NMDAR) expression in most parts of the brain $[3,4]$, together with the fact that degradation of D-serine abolishes NMDAR neurotransmission in different brain regions [5,6], supported the notion that $\mathrm{D}$-serine is an important endogenous ligand for the NMDAR, participating broadly in synaptic events associated with development, plasticity, learning,

\footnotetext{
* Correspondence: bargerstevenw@uams.edu

'Department of Geriatrics, University of Arkansas for Medical Sciences, Little Rock AR 72205, USA

Full list of author information is available at the end of the article
}

memory and excitotoxicity. Mice bearing a loss-of-function mutation in SR or targeted deletion of the gene show an $80-90 \%$ decrease in brain D-serine levels $[7,8]$. They also display behavioral phenotypes relevant to schizophrenia, including deficits in spatial object discrimination and long-term memory. These findings are consistent with compelling evidence that NMDAR hypofunction contributes to schizophrenia [9], as well as less complete data implicating D-serine deficiencies in this important human disorder [10]. In addition, evidence indicates that SR is directly involved in age-related deficits in hippocampal cognitive function [11] and the pathogenesis of amyotrophic lateral sclerosis [12].

Highly conserved in mammalian species, SR is a pyridoxal-5'-phosphate (PLP)-dependent enzyme which directly converts L-serine to D-serine. Enzymology studies of SR reveal that SR activity is modulated in many ways by various factors. SR activity is elevated by PLP [2], magnesium, ATP [13,14], calcium [15], and D-serine $[16,17]$; inhibition of SR activity has been reported for
C Biomed Central

(C) 2011 Wang and Barger; licensee BioMed Central Ltd. This is an Open Access article distributed under the terms of the Creative Commons Attribution License (http://creativecommons.org/licenses/by/2.0), which permits unrestricted use, distribution, and reproduction in any medium, provided the original work is properly cited. 
NO [16-18], glycine [19,20], and membrane lipids like PIP2 [21]. Furthermore, SR activity is augmented by physical interactions with other proteins, such as glutamate-receptor-interacting protein (GRIP) [22,23] and protein interacting with $C$ kinase (PICK1) $[24,25]$.

We previously found that proinflammatory conditions in microglia elevated the steady-state levels of an SR dimer that was apparent even in reducing, denaturing gel electrophoresis [26,27]. This phenomenon was accompanied by elevated production of D-serine, suggesting that this stable dimer was responsible for high specific activity. The native structure of recombinant mouse SR was determined by gel-filtration chromatography to exist in a dimer-tetramer equilibrium in solutions [15]. Native SR purified from mouse brain has a relative mobility consistent with a mass of $55 \mathrm{kDa}$, which is assumed to be a dimer [13]. Recently, the crystal structures of human and rat SR preparations with two mutations (C2D, C6D) also indicated a dimeric structure for this enzyme [28]. It has been reported that oxidation of sulfhydryl groups inhibits SR activity [2,15], but how the redox state of sulfydryl groups affects SR structure is unknown. In this study, the relationship between the structure and activity of SR by reducing and oxidizing sulfydryl group was investigated.

\section{Results}

Purification and enzymatic characterization of recombinant human SR

For these studies, SR cDNA was amplified by RT-PCR from human RNA and cloned into pTrcHisB, a prokaryotic expression vector that encodes an in-frame polyhistidine domain at the protein's $\mathrm{N}$-terminus. Expressed protein was purified on a nickel-charged affinity resin. Expression of the protein yielded about $4 \mathrm{mg}$ of purified protein from $1 \mathrm{~L}$ of bacteria culture. The protein in each fraction collected from affinity columns was detected by SDS-PAGE, which showed a very dense band of SR at $40 \mathrm{kDa}$ (the approximate molecular weight of human SR monomer with the polyhistidine fusion) and indicated that this strategy of affinity chromatography provided protein that was $\sim 90 \%$ pure.

The activity of purified SR was assessed for MichaelisMenten kinetics (Figure 1), which indicated a $K_{M}$ value of $14 \mathrm{mM}$ when $\mathrm{L}$-serine was used as a substrate. The $\mathrm{V}_{\max }$ of SR was $3.66 \mu \mathrm{mol} \cdot \mathrm{mg}^{-1} \cdot \mathrm{hr}^{-1}$ at $37^{\circ} \mathrm{C}$. These results are similar to data reported previously for recombinant mouse SR protein and purified SR from mouse brain $[2,15]$.

\section{Oligomeric structure of SR}

To study the oligomeric structure of SR under native conditions, recombinant SR eluted from affinity column was loaded on a gel-filtration column (Superdex HR200) which resolves proteins in approximately the 10- to 600$\mathrm{kDa}$ molecular-mass range. The elution profile of SR is depicted in Figure 2. Calibration of the column using protein standards and interpolation of the elution volume of SR gave theoretical molecular masses for SR peaks. The first peak eluted at $8.05 \mathrm{~min}$, which fell into the void volume of the column determined by blue dextran, representing a large protein aggregate. The second peak at $11.55 \mathrm{~min}$ with theoretical molecular mass 189 $\mathrm{kDa}$ probably indicates a tetramer. The third peak at

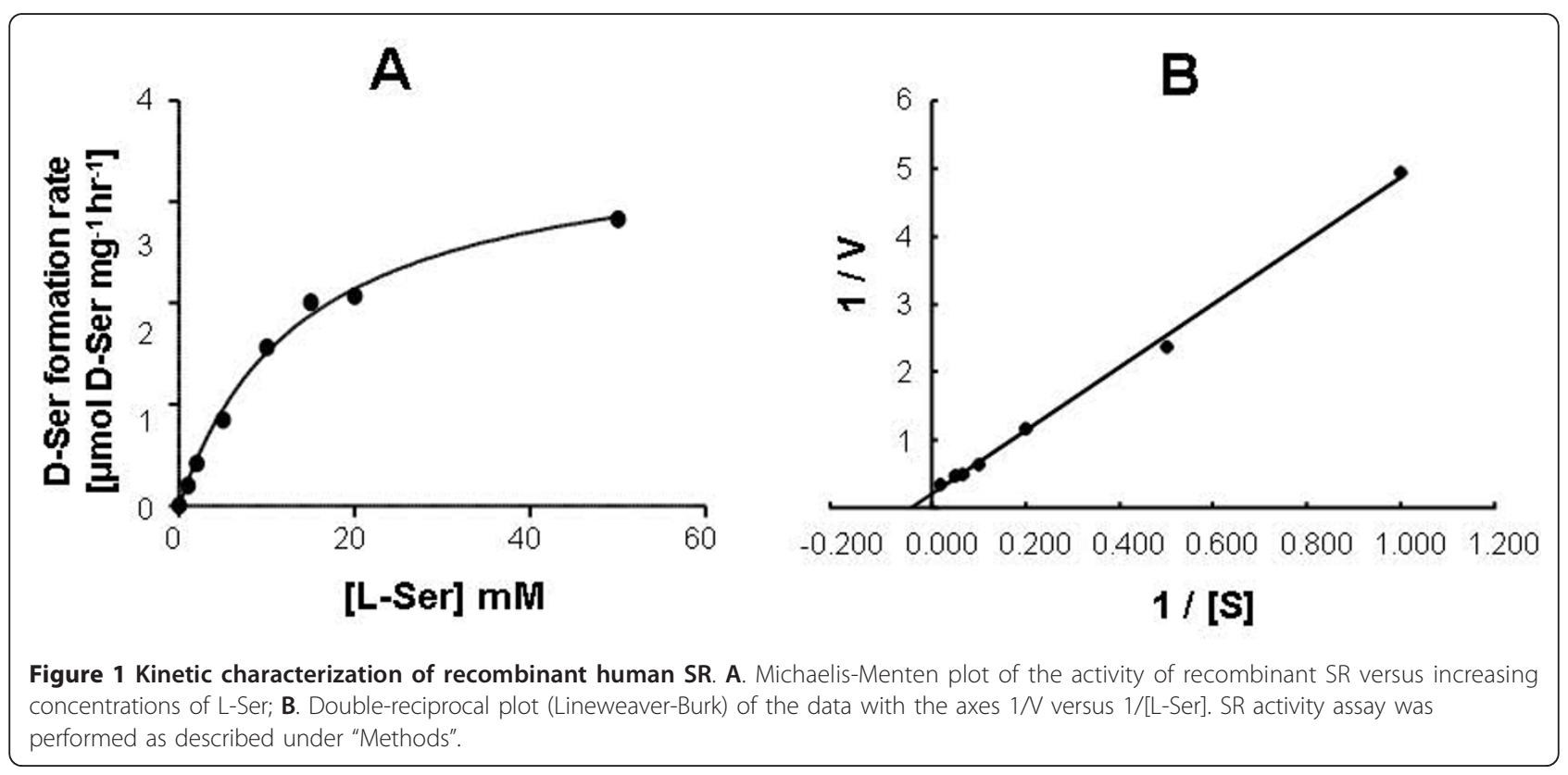




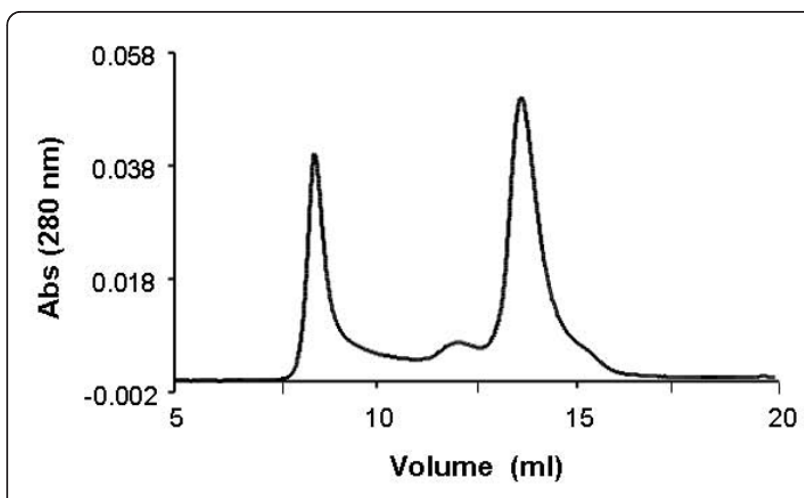

Figure 2 Gel-filtration chromatography of recombinant SR Purified recombinant SR with affinity column was extensively dialyzed against $50 \mathrm{mM}$ phosphate buffer, $\mathrm{pH} 8.0,52 \mathrm{mM} \mathrm{NaCl}$. After concentration with Centricon filters, aliquots of $50 \mu \mathrm{l}$ of $\sim 3$ $\mathrm{mg} / \mathrm{ml}$ of recombinant SR were loaded onto a Superdex HR200 gelfiltration column. Separation was performed at $25^{\circ} \mathrm{C}$ with flow rate at $0.5 \mathrm{ml} / \mathrm{min}$. The elution buffer was the same as dialysis buffer. Protein detection was performed at $280 \mathrm{~nm}$.

13.30 min with theoretical molecular mass $87.5 \mathrm{kDa}$ likely represents a dimer. The forth peak appears as a shoulder on the third peak at $14.85 \mathrm{~min}$; its theoretical molecular mass of $45.35 \mathrm{kDa}$ suggests the monomer. The results from gel filtration revealed that dimer is the major oligomeric structure of recombinant SR. There are, however, small amounts of tetrameric and monomeric SR in solution.

To confirm the dimeric structure of SR, we fixed protein quaternary structure by using protein cross-linker bis(sulfosuccinimidyl)suberate $\left(\mathrm{BS}^{3}\right) . \mathrm{BS}^{3}$ contains an amine-reactive $\mathrm{N}$-hydroxysulfosuccinimide (NHS) ester at each end of an 8-carbon spacer arm, which reacts with protein primary amines at $\mathrm{pH}$ 7-9 to form amide bonds resistant to SDS and reducing reagents. First, $\mathrm{BS}^{3}$ was applied to cross-link recombinant SR. The SDSPAGE (Figure 3A) after the cross-linking reaction showed that with increasing concentrations of $\mathrm{BS}^{3}$, SR monomer decreased while dimeric band became denser, indicating that dimer is present in recombinant SR preparations. There was a faint band just above $170 \mathrm{kDa}$ when SR was treated with 10,30 or $100 \mu \mathrm{M} \mathrm{BS}^{3}$, which may be cross-linked SR tetramer. In addition, one crosslinked band was observed between $100 \mathrm{kDa}$ and 130 $\mathrm{kDa}$; this may be formed by dimeric SR and a small contaminating bacteria protein, based on preliminary sequencing data (unpublished results). In addition to these bands, there were a few high molecular-weight aggregates formed during the cross-linking reaction which were trapped in sample loading wells. To study the quaternary structure of SR in cellular cytosol, $\mathrm{BS}^{3}$ was applied to cytosol extracted from mouse primary astrocytes. After cross-linking reactions, western blot analysis with anti-SR antibody showed that $\mathrm{BS}^{3}$ treatment decreased SR monomer while increasing its dimeric form (Figure 3B), suggesting that SR dimer is also a product of its normal cellular environment.

\section{Dimer is more active than monomer}

Several different buffers have been used to purify recombinant SR in previously published studies. The effects of Tris-based and phosphate-based buffers on SR activity and structure were tested here. First, SR was purified with affinity chromatography and dialyzed against a phosphate buffer $(50 \mathrm{mM}$ sodium phosphate, $\mathrm{pH} 8.0,52 \mathrm{mM} \mathrm{NaCl})$ or a Tris buffer $(50 \mathrm{mM}$ Tris$\mathrm{HCl}, \mathrm{pH}$ 8.0, $150 \mathrm{mM} \mathrm{NaCl})$. SR in each buffer was

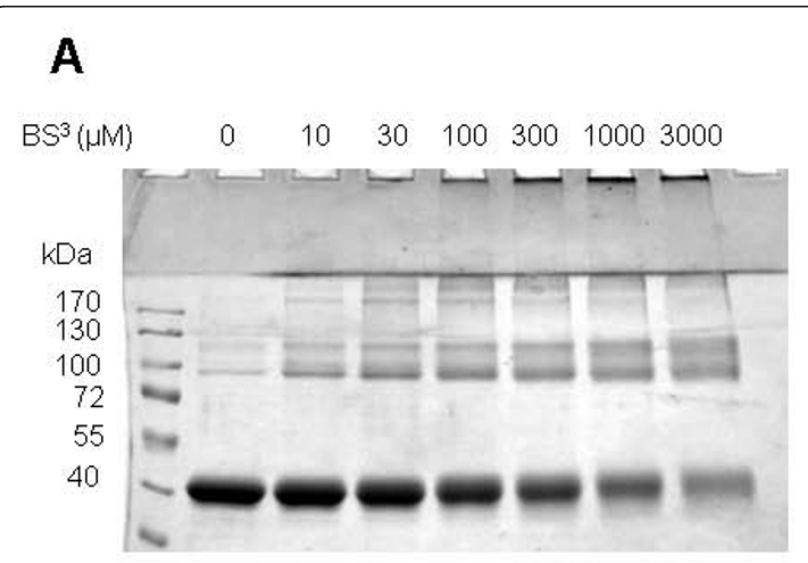

\section{B}

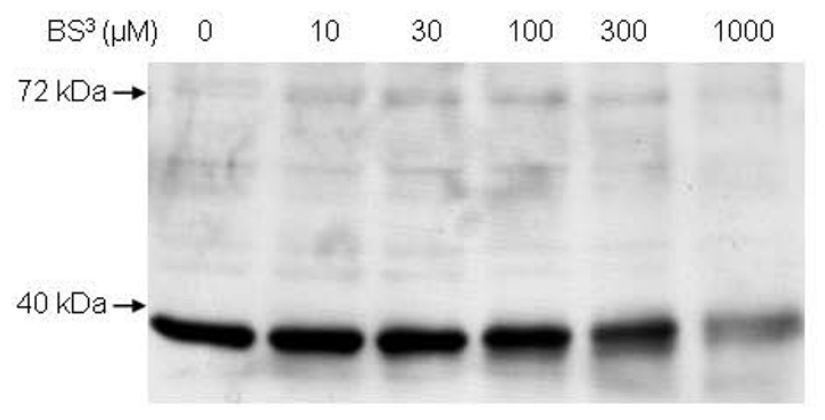

Figure 3 Stabilization of in vitro- and in vivo-formed multimers by chemical cross-linker. A. Increasing concentrations of $\mathrm{BS}^{3}$ were incubated with $12.5 \mu \mathrm{M}$ recombinant SR on ice for $2 \mathrm{~h}$, then the reactions were quenched by addition of Tris-HCl. Reaction samples were analyzed on 10\% SDS-PAGE with $2.5 \% \beta$-mercaptoethanol in the sample buffer. $\mathbf{B}$. Increasing concentrations of protein cross-linker $\mathrm{BS}^{3}$ were incubated with lysates from mouse primary astrocytes $(0.5 \mu \mathrm{g}$ protein $/ \mu \mathrm{l})$ on ice for $2 \mathrm{~h}$, and the reactions were quenched by the addition of Tris-HCl. The formation of cross-linked SR protein was analyzed by western blot with an anti-SR antibody. 
assessed for activity (Figure 4). Michaelis-Menten analysis revealed a $\mathrm{K}_{\mathrm{M}}$ of $14 \mathrm{mM}$ in phosphate buffer and 24 $\mathrm{mM}$ in Tris buffer; the $\mathrm{V}_{\max }$ of the enzyme was 3.66 $\mu \mathrm{mol} . \mathrm{mg}^{-1} . \mathrm{hr}^{-1}$ in phosphate buffer and $2.06 \mu \mathrm{mol} . \mathrm{mg}^{-1}$. $\mathrm{hr}^{-1}$ in Tris buffer (Table 1). These results indicated that in phosphate buffer SR has higher affinity to L-serine and greater velocity of racemization reaction than in Tris buffer.

To determine what structural change(s) resulted in such a difference in kinetic character of SR in these two buffers, the oligomeric structure of SR was analyzed with gel-filtration chromatography (Figure 5). Interestingly, the elution profiles showed that in phosphate buffer the major conformation of SR was dimer along with a small amount of tetramer, while in Tris buffer the major species was monomer with a small dimer peak. Also, the percentage of large protein aggregates was greater in Tris buffer than in phosphate buffer. To confirm that this difference was not caused by the chromatography itself or other experimental manipulations, 3(N-morpholino)propanesulfonic acid (MOPS) was used as the buffer in a gel-filtration separation. The results in MOPS buffer were similar to those in phosphate buffer: a large dimer peak and a small tetramer peak (data not shown).

Because the SR monomer peak in phosphate buffer and SR dimer peak in Tris buffer were small, it was impossible to compare dimer and monomer activity in either single buffer. Moreover, isolated monomer or dimer might be expected to re-equilibrate to a proportional mixture of the two after fractionation. But the

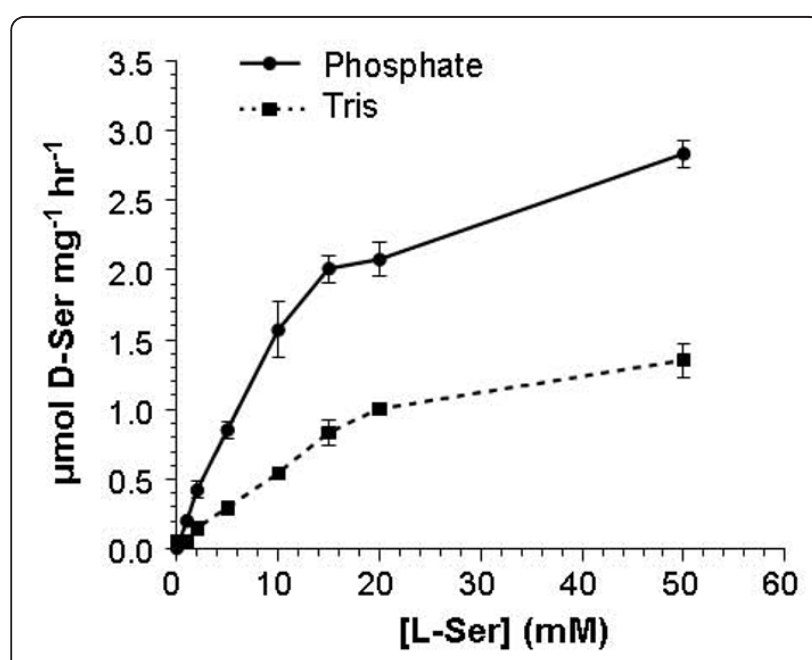

Figure 4 Influence of buffer components on SR activity. Recombinant SR purified by affinity chromatography was dialyzed against a phosphate-buffered (solid line) or Tris-buffered solution (dashed line). Then, SR activity of each enzyme preparation was monitored as described under "Methods" except for the reaction buffers, which corresponded to each respective dialysis buffer.
Table 1 Effect of buffer components on SR activity.

\begin{tabular}{lll}
\hline & Phosphate & Tris \\
\hline $\mathrm{K}_{\mathrm{M}}(\mathrm{mM})$ & $14 \pm 1.5$ & $24 \pm 4.0$ \\
\hline$V_{\max }(\mu \mathrm{mol} \mathrm{mg-1} \mathrm{hr-1)}$ & $3.664 \pm 0.166$ & $2.056 \pm 0.180$ \\
\hline
\end{tabular}

differing effects of Tris and phosphate buffers on SR quaternary structure provides an opportunity to examine mixtures in which the proportion of dimer differs stably. Gel-filtration fractions of the dimer eluted with phosphate buffer and monomer eluted with Tris buffer were collected and compared in an enzyme activity assay with $10 \mathrm{mM} \mathrm{L-Ser}$. The dimeric preparation produced D-Ser at a rate of $0.253 \pm 0.047 \mu \mathrm{mol} \cdot \mathrm{mg}^{-1} \cdot \mathrm{hr}^{-1}$, whereas the value for the monomeric preparation was $0.108 \pm 0.010$ $\mu \mathrm{mol} . \mathrm{mg}^{-1} \cdot \mathrm{hr}^{-1}(p \leq 0.01)$.

\section{Cysteine residues are critical to activity and structure of SR}

Protein resolving as dimeric in gel-filtration chromatography could potentially include covalent and/or noncovalent dimers. Human SR has eight cysteine residues, creating ample opportunity for a variety of redox-based modifications including disulfide bonds. Such disulfides could act as a bridge to create covalent dimers of SR when occurring intermolecularly, but even intramolecular disulfides could place conformational restraints on the protein's structure. In addition, the free thiol group of a cysteine residue is important for the enzymatic mechanism of many enzymes. We tested the roles of

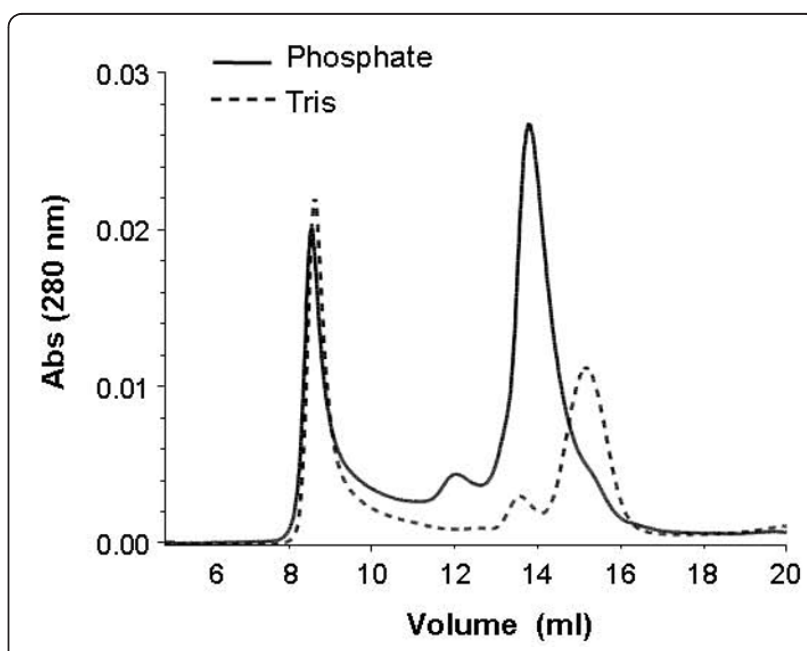

Figure 5 Influence of buffer components on quaternary structure of recombinant SR. Recombinant SR purified by affinity chromatography was dialyzed against a phosphate-buffered (solid line) or Tris-buffered solution (dashed line). After concentration with Centricon filters, $50-\mu$ l aliquots of $\sim 3 \mathrm{mg} / \mathrm{ml}$ of each recombinant SR were loaded onto a Superdex HR200 gel-filtration column and eluted with same buffer as the corresponding dialysis buffer. 
SR's cysteine residues through a coordinated manipulation of redox status and utilization of sizing chromatography.

In preparations of recombinant SR purified only through the initial step of nickel affinity chromatography, reactions containing the thiol-reducing reagent DTT showed higher enzymatic activity; this effect was manifested as a dramatic increase in $\mathrm{V}_{\max }$ (Figure 6). The effect of DTT on SR quaternary structure was assessed with gel-filtration chromatography. The elution profile revealed that DTT decreased the amounts of both the large aggregate and the tetramer while increasing the amount of dimer; monomer amounts were virtually unchanged (Figure 7).

These results suggest that some of the SR in aggregate and tetramer pools was multimerized by covalent disulfide bonds. This conclusion was supported by western blot analysis of SR eluted directly from the nickel affinity column (Figure 8A) or of dimeric fractions eluted from the gel-filtration column (Figure 8B). For the initial SR preparation obtained from the nickel affinity column, dialysis in the presence of DTT produced protein that entirely denatured to monomer in the presence of SDS. Dialysis in the absence of DTT produced protein that was resolved by non-reducing SDS-PAGE into large aggregates, tetramer, and dimer. These multimers were partially reduced to monomer when DTT was included in the SDS-PAGE sample buffer. Similar results were

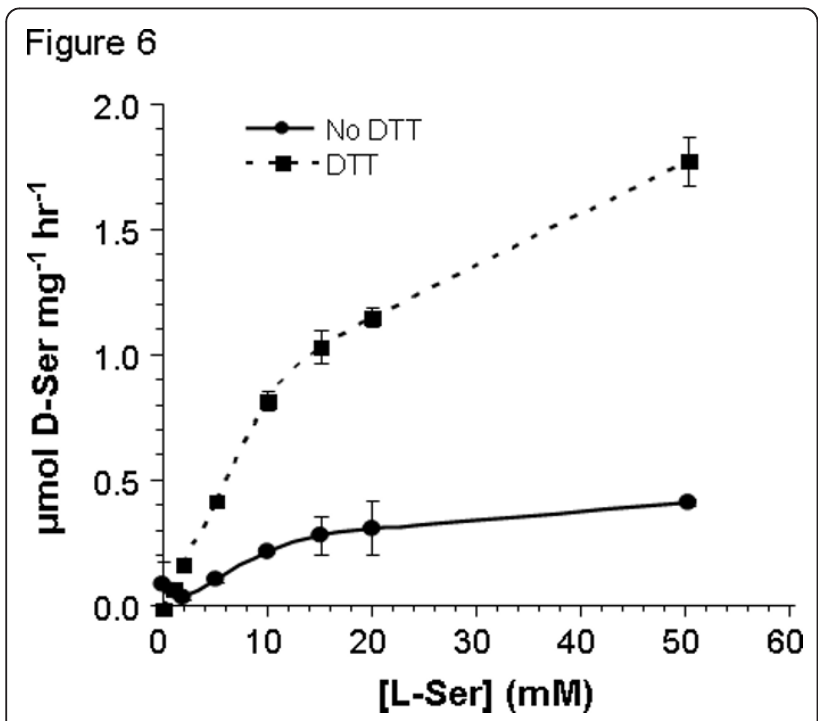

Figure 6 Chemical reduction elevates SR activity by increasing its $\mathbf{V}_{\text {max }}$. SR activity assay was performed in the phosphate buffer with $2.5 \mu \mathrm{g}$ recombinant enzyme and the indicated concentrations of L-serine; DTT was alternatively excluded (solid line) or included (dashed line) at $0.2 \mathrm{mM}$. After incubation at $37^{\circ} \mathrm{C}$ for $30 \mathrm{~min}$, the reaction was terminated by boiling for $5 \mathrm{~min}$. D-ser formation was monitored by a chemiluminescence assay. The data are representative of three different protein preparations.

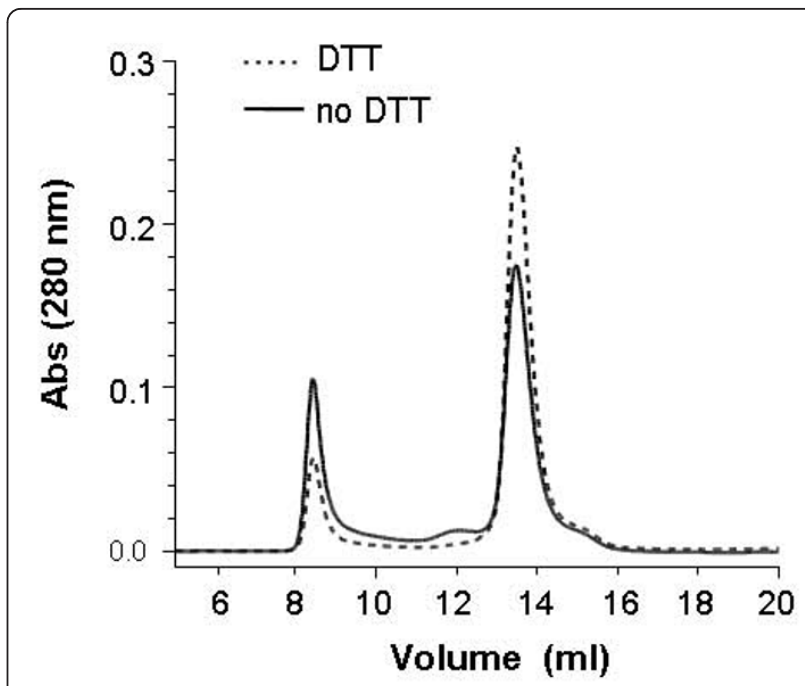

Figure 7 Effect of chemical reduction on quaternary structure of recombinant SR: native conditions. Recombinant SR purified by affinity chromatography was dialyzed against the phosphate buffer with (dashed line) or without (solid line) $0.2 \mathrm{mM}$ DTT. After concentration with Centricon filters, $50-\mu$ l aliquots of $\sim 10 \mathrm{mg} / \mathrm{ml}$ of each recombinant SR were injected onto a Superdex 200 column and eluted with the same buffer as the dialysis buffer.

seen with dimeric SR obtained from the gel-filtration column with or without DTT in the chromatography buffer.

To assess the role of covalent bonds in activity, we compared the activities of SR dimeric fractions eluted from the gel-filtration column with or without DTT added to the chromatography buffer (Figure 9). The activity of SR dimer in the presence of DTT was significantly greater than that of dimer lacking DTT. Addition of DTT into the reaction buffer enhanced the activity of dimer purified without DTT, but this step still produced lower activity than dimer purified in the presence of DTT; this relative ranking generally reflected the level of SR isolated as dimer under native conditions but appearing as monomer in SDS-PAGE (Figure 8B), i.e., non-covalent dimer.

To investigate the relevance of disulfide bonds for SR in a cellular context, lysates of mouse primary astrocytes were resolved under non-reducing (Figure 10A) and reducing (Figure 10B) SDS-PAGE. SR protein was detected by western blot analysis. SR monomer was detected only under reducing conditions. Combined with the results of cross-linking experiments (Figure 3B), these data indicate that intermolecular disulfide bonds could be formed in native SR dimers, at least when intracellular redox status is altered, e.g., after depletion of glutathione or aberrant production of reactive oxygen species.

The conformational consequences of disulfides are apparent from the above data, but other types of 


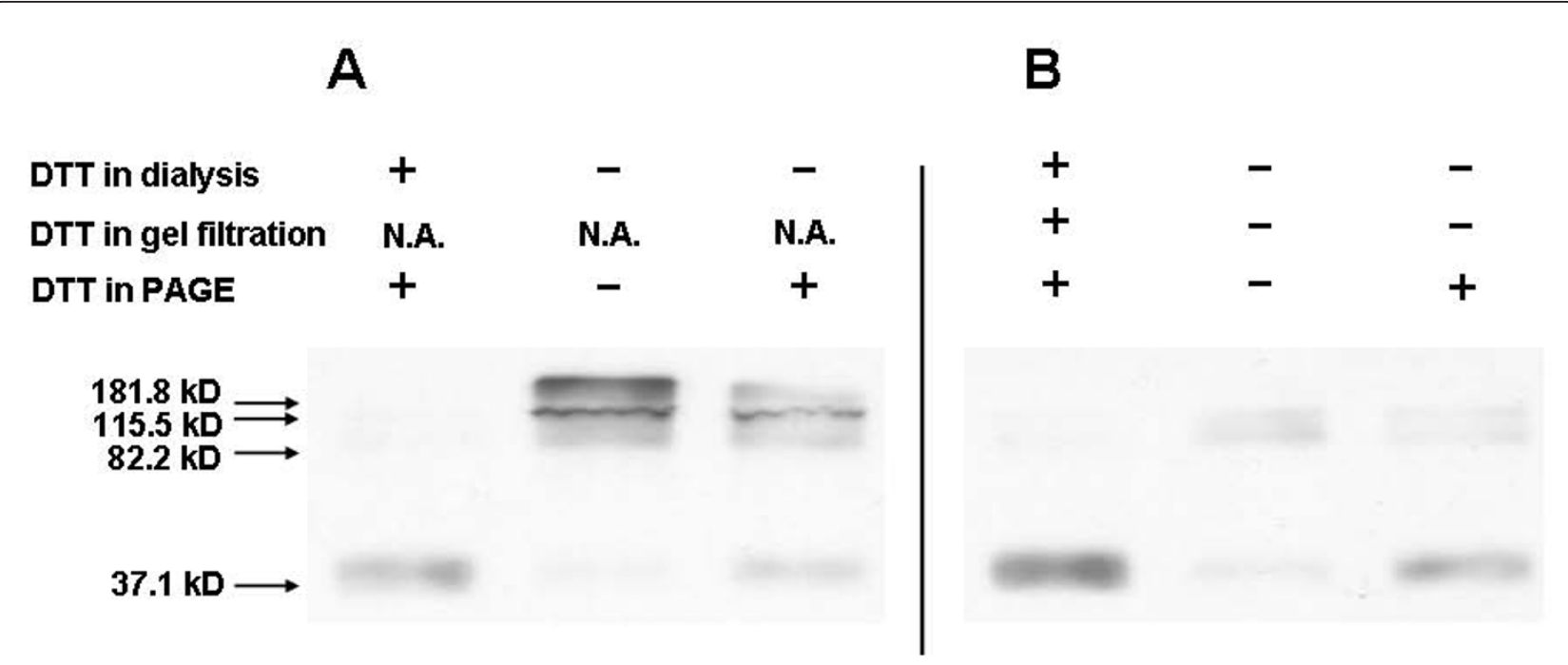

Figure 8 Effect of chemical reduction on quaternary structure of recombinant SR: denaturing conditions. A. Recombinant SR waS dialyzed against phosphate buffers with or without $0.2 \mathrm{mM}$ DTT after elution from the nickel affinity column. B. SR preparations in panel A were injected onto a Superdex HR200 column and eluted with same buffer as the corresponding dialysis buffer. Recombinant SR oligomeric species of both protein preparations in A and B were subjected to SDS-PAGE in presence or absence of $0.2 \mathrm{mM}$ DTT in the sample loading buffer. The gels were then immunoblotted with anti-SR antibody.

oxidation of cysteine thiols can also impact their participation in the catalytic mechanism of an enzyme. To further address the role of free sulfhydryl groups in catalysis, we tested the effect of cystamine, a reagent capable of blocking free thiol groups. Cystamine dramatically inhibited the activity of SR dimers (Figure 9).

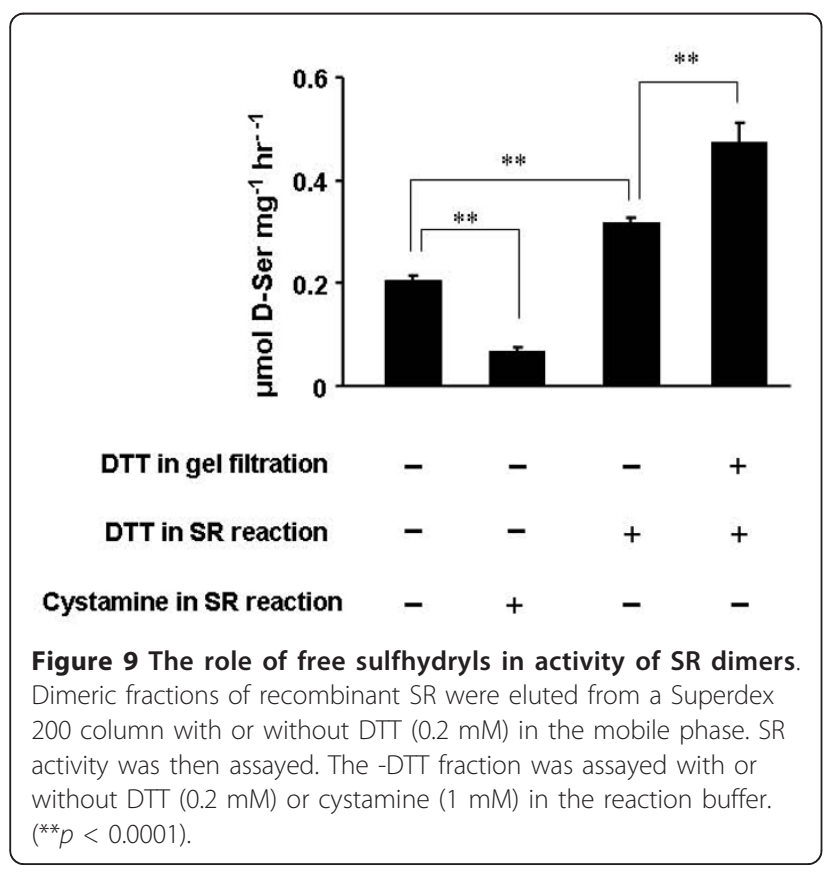

\section{Discussion}

Physiological activation of the NMDARs requires ligation of both the glutamate binding site (on NR2 subunits) and what has been termed the "glycine ${ }_{\mathrm{B}}$ " site (on NR1 subunits). There is considerable evidence that the dominant agonist for the NR1 site in most parts of brain is not glycine but D-serine $[3,4]$. As the only known enzyme to synthesize this novel neurotransmitter in vivo, SR has drawn increasing attention for its role

Figure 10

A

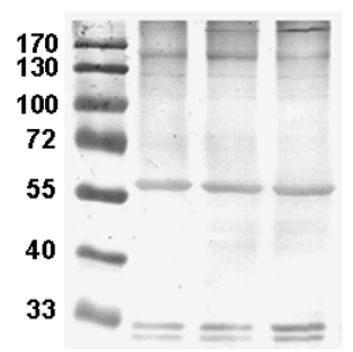

B

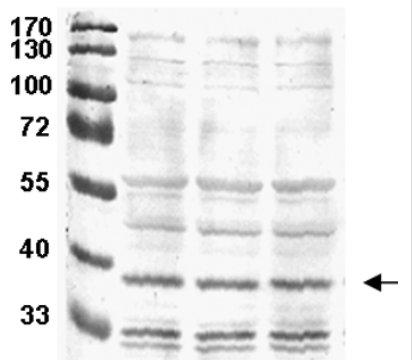

Figure 10 SR protein from a cellular source oxidizes to dimers and other multimers. Total cellular protein was prepared from three cultures of mouse primary astrocytes and resolved by $10 \%$ SDS-PAGE in the absence (A) or presence (B) of $2.5 \% \beta$ mercaptoethanol in the sample buffer. SR protein (arrow) was detected by western blot with anti-SR antibody. Lane 1 contained molecular weight standards $(\mathrm{kDa})$. 
involved in regulation of $\mathrm{D}$-serine synthesis and modulation of glutamatergic synapse activity. In this study we describe the relationship between structural and functional characterization of SR.

Gel-filtration chromatography and cross-linking experiments demonstrated that the major oligomeric structure of recombinant human SR is a dimer. Crosslinking experiments in cell culture also suggested that SR dimer is present in intact cells. One surprising discovery is that recombinant SR had different oligomeric compositions in Tris- and phosphate-based buffers. In phosphate buffer SR is predominantly dimer with a small amount of tetramer, whereas in Tris buffer the major species is monomer with a small dimer peak. By contrast, Smith et al. [28] reported that recombinant SR based on the human and rat sequences were dimeric during gel-filtration chromatography with a Tris-based buffer. This distinction may involve differences in the SR primary sequence. Smith et al. introduced missense mutations $\left(\mathrm{Cys}_{2} \rightarrow \mathrm{Arg}\right.$ and $\left.\mathrm{Cys}_{8} \rightarrow \mathrm{Arg}\right)$ in order to improve solubility because their production yield was low. Because cysteine residues are so important for SR activity and structure-particularly quaternary structurethose mutants are not comparable to the wild-type sequence we used. In another case, SR was extracted and sequentially purified from mouse brain with an anion-exchange column in Tris- $\mathrm{HCl}$ buffer, a Q-sepharose column in Tris- $\mathrm{HCl}$ buffer, and hydroxylapatite column in phosphate buffer [13]. The enzyme was then resolved with a gel-filtration column in Tris- $\mathrm{HCl}$ buffer, which indicated a species with an apparent size of 55 $\mathrm{kDa}$. Because $55 \mathrm{kDa}$ is between the sizes expected for monomer $(37 \mathrm{kDa})$ and dimer $(74 \mathrm{kDa})$, this finding is difficult to interpret. Though the reason for the buffer's effect is still unknown, this phenomenon permitted a comparison of activity across conditions that favor monomer versus dimer formation. The results support the conclusion that dimer has higher activity as phosphate buffer resulted in both more dimer and more activity. In addition, phosphate buffer is probably closer to physiological conditions than is Tris. Thus, phosphate buffers would seem more appropriate than Tris buffers for biochemical analysis of SR.

The effects of DTT on SR's activity are prominent. The influence of DTT on enzyme's structure includes two possibilities: First, DTT may keep the thiol group of critical cysteine residue(s) in a reduced state. The critical residue(s) may reside in the active site of the enzyme and be important in catalysis of enzyme reactions or reside outside the active site and be critical in modulating the enzyme reactions allosterically. Second, DTT may prevent or break randomly formed disulfide bonds between cysteine residues outside of the active center, thereby helping the protein to fold correctly during synthesis/purification in this recombinant system.

Blocking of free sulfhydryl groups by cystamine dramatically decreased SR activity, which indicates a key role for a cysteine residue(s) in the active site and/or a modulatory site. One previous study [18] mentioned that murine SR protein with $\mathrm{Cys}_{217} \rightarrow$ Ser mutation is basally inactive, which may indicate that $\mathrm{Cys}_{217}$ is located in the SR active site and involved in catalysis. Also, Cys $\mathrm{C}_{113}$ in mouse SR was reported to be S-nitrosylated by $\mathrm{NO}$ to form S-nitrosothiol (SNO), leading to a dramatic inhibition of enzyme activity [18]. Structural analysis reveals that the ATP-binding site is in close proximity to $\mathrm{Cys}_{113}$, and nitrosylation of $\mathrm{Cys}_{113}$ interferes with ATP binding to SR [18]. If the structure of the free thiol group of $\mathrm{Cys}_{113}$ is critical for ATP binding to SR, other types of covalent modification of $\mathrm{Cys}_{113}$ including a disulfide bond between $\mathrm{Cys}_{113}$ and any other cysteine residue is very likely to have the same effect on ATP binding as nitrosylation of $\mathrm{Cys}_{113} \cdot \mathrm{Cys}_{217}$ and Cys $_{113}$ are both conserved evolutionarily, suggesting that disulfide bonds between these residues, either intra- or intermolecularly, accounts for the cross-species similarities documented by Mustafa et al. vis-à-vis our results.

In addition to S-nitrosylation, cysteine residue can undergo a broad range of post-translational redox modifications by diverse reactive oxygen species (ROS) and reactive nitrogen species (RNS). The ability to cycle between different redox states and the specificity toward oxidative reactions endow the cysteine residue with properties consistent with it being a participant in redox-based physiological signal transduction or modulation [29]. Hydrogen peroxide can oxidize the cysteine residue in the catalytic center of protein tyrosine phosphatases (PTPs) to sulphenic acid (S-OH), abolishing the catalytic activity of the cysteine residue as a phosphate acceptor [30]. RNS such as NO and peroxynitrite are reportedly able to produce sulphenic acid in the oxidation of thiol compounds [31]. In many cases, sulphenic acid reacts rapidly with other cysteine thiols to form disulfide bonds (S-S). These disulfide bonds can be formed either intramolecularly or intermolecularly, the latter connecting two subunits in one complex or two different quaternary complexes.

As the major covalent connection between peptides, the disulfide bond plays a very important role in protein folding, polymerization, and activity regulation [32], which was also tested in SR here. Under some circumstances, a mixed disulfide bond is formed between cysteine residues in proteins and the small molecule glutathione, an event known as S-glutathionylation (protein-SSG). Accumulating evidence implicates Sglutathionylation in many pathological conditions such as neurodegenerative diseases, cancer, lung diseases, 
cardiovascular diseases, and diabetes [33]. Under conditions of a robust oxidative burst, sulphenic moieties of cysteine residues can be progressively oxidized to sulphinic acid $\left(\mathrm{R}-\mathrm{SO}_{2} \mathrm{H}\right)$ and sulphonic acid $\left(\mathrm{R}-\mathrm{SO}_{3} \mathrm{H}\right)$. While $\mathrm{S}$-nitrosothiol (SNO), sulphenic acid (S-OH), disulfide bonds (S-S), and S-glutathionylation (protein-SSG) can be reduced by glutathione and/or thioredoxin in biological system, formation of sulphinic acid $\left(\mathrm{R}-\mathrm{SO}_{2} \mathrm{H}\right)$ and sulphonic acid $\left(\mathrm{R}-\mathrm{SO}_{3} \mathrm{H}\right)$ is believed to be irreversible. Hence, these two hyperoxidized thiol moieties are not considered to be involved in reversible redox signaling [34].

This study also supports the second potential effect of DTT on the enzyme's structure: creating conditions permissive for optimal flexibility of the structure. DTT facilitated release of non-covalent dimer from large aggregates and tetramers, suggesting that during substrate binding and/or catalysis, SR enzyme may need to change its conformation to make the active center more suitable for substrate and the positions of critical amino acids more accurate for catalysis. This is confirmed by recent findings from a SR crystallization study [28], which demonstrated that the tertiary structure of SR has large and small domains connected by a loop region. During the racemization reaction, the small domain appears capable of a large degree of flexibility to correctly orientate the substrate L-serine close to active site for catalysis. Compared to non-covalent dimer, disulfide-linked dimer is less likely to change conformation freely, which may explain its lower catalytic ability. Thus, the flexibility of the enzyme protein appears to be important for its function.

We previously found that inflammatory activation of microglia elevated the levels of a stable SR dimer and D-serine production $[26,27,35]$. This finding suggested that an apparent covalent dimer was responsible for enzymatic activity. Activation of microglia typically involves a programmatic superoxide production from NADPH oxidase, and this dramatically enhances the oxidation conditions in the cells. It is possible that these conditions result in oxidative crosslinking of the SR subunits. This may involve disulfide bonds, but the species induced by microglial activation was stable to DTT and $\beta$-mercaptoethanol. Moreover, the data reported here indicate that disulfide-linked dimers are actually less active than noncovalent dimers, arguing against any connection between formation of the stable dimer and elevated D-serine production in activated microglia. It seems more likely, therefore, that the stable dimer observed in activated microglia results from some chemical conjugation of amino acids other than cystine disulfides. For example, superoxide dismutase has been found to aggregate through several forms of covalent bonds arising from a tryptophanyl radical [36]. It is possible that microglial activation initially results in an elevation of SR expression (via the AP-1 transcription factor, as described [27]), a substantial fraction of which would be active, noncovalent dimer. The subsequent oxidative conditions may then crosslink these dimers via as yet undefined reactions.

\section{Conclusions}

We have obtained data confirming that human serine racemase is most active as a noncovalent dimer. The optimal catalytic activity of the enzyme appears to contain one or more free sulfhydryls; these may be located in the active site or they may effect modulation allosterically. Likely owing to these sulfhydryls, reduction/oxidation status during production and purification of SR can dramatically impact specific activity. We also documented a surprising effect of buffer composition on activity, providing cautionary information for interpretations of SR activity. The structural characteristics of SR obtained from live cells suggest that SR is sensitive to oxidation in vivo, perhaps consistent with a scenario in which such modification plays a role in feedback or other forms of regulation.

\section{Methods}

\section{Recombinant expression of human SR}

Full-length SR cDNA was obtained by reverse transcription-polymerase chain reaction (RT-PCR) from human brain mRNA. Two oligonucleotides were used to amplify the cDNA: forward primer, 5'-ATA GGA TCC TGA GCT GAG AAC CAT GTG TG-3' and reverse primer, 5'-GGA AAT GGT GGG AAT TCA GTG GAT CCT AT- 3', where novel BamHI sites (underlined sequences) were introduced before the initiation Met residue and after the "stop" codon. The amplified fragment of DNA (1085 bp) was digested with BamHI and subcloned into pcDNA3.1 plasmid (Invitrogen). The pcDNA3.1-SR plasmid was then digested with BamHI, and the excised fragment of DNA was ligated into the corresponding sites of the pTrcHisB expression vector (Invitrogen). After DNA sequence verification, pTrcHisB-SR vector was transformed into competent BL21 (DE3) E. coli (Invitrogen). A 20-ml overnight culture was grown and used to inoculate $480 \mathrm{ml}$ of fresh Luria-Bertani (LB) medium containing $50 \mu \mathrm{g} / \mathrm{ml}$ carbenicillin (Sigma). Typically, the cultures were grown at $37^{\circ} \mathrm{C}$ with shaking until they reached mid-log $\left(\mathrm{OD}_{600}=\right.$ 0.6). Expression from the pTrcHisB-SR vector was then induced by the addition of $0.75 \mathrm{mM}$ isopropyl-1-thio- $\beta$ D-galactopyranoside (IPTG, Fisher Scientific), and the culture was incubated for an additional $3-4 \mathrm{~h}$ at $37^{\circ} \mathrm{C}$. The cells were collected by centrifugation at $3500 \mathrm{rpm}$ for $30 \mathrm{~min}$ and stored at $-80^{\circ} \mathrm{C}$. 


\section{Purification of recombinant human SR}

The frozen cell pellet was resuspended in native binding buffer (50 mM phosphate buffer, $\mathrm{pH} 8.0,52 \mathrm{mM} \mathrm{NaCl}$ ) with $1 \mathrm{mg} / \mathrm{ml}$ lysozyme on ice, and the cells were lysed by sonication (six cycles of $30 \mathrm{~s}$ with a 30-s cooling period on ice between each cycle). The supernatant of the lysate was obtained by centrifugation at $12,000 \times \mathrm{g}$ for $40 \mathrm{~min}$. All the purification steps were performed at 0 $4^{\circ} \mathrm{C}$. Because the pTrcHisB-SR vector has a hexahistidine tag translated at the $\mathrm{N}$-terminus of SR, purification of the protein was initially performed by affinity chromatography. The cellular supernatant was loaded on to a 5-ml ProBond ${ }^{\mathrm{TM}}$ nickel-chelating resin column (Invitrogen). The column was washed with $40 \mathrm{ml}$ wash buffer (50 mM phosphate buffer, $\mathrm{pH} 8.0,52 \mathrm{mM} \mathrm{NaCl}$, and $100 \mathrm{mM}$ imidazole). Then the protein was eluted with elution buffer (50 mM phosphate buffer, pH 8.0, $52 \mathrm{mM}$ $\mathrm{NaCl}$, and $250 \mathrm{mM}$ imidazole). The recombinant SR in each fraction was detected by sodium dodecyl sulphate polyacrylamide gel electrophoresis (SDS-PAGE). Fractions with highest concentrations of SR were pooled together and extensively dialyzed against the assay buffer's base [50 mM phosphate buffer, $\mathrm{pH} 8.0,52 \mathrm{mM}$ $\mathrm{NaCl}, 0.2 \mathrm{mM}$ DTT (Fisher Scientific)], first with Tween-20 (0.1\%) and then without. After dialysis, proteins were kept at $4^{\circ} \mathrm{C}$ for structure and activity analysis.

\section{Enzyme assay}

The activity of SR was measured by the velocity of racemization reaction of $\mathrm{L}$-serine to $\mathrm{D}$-serine, the latter of which was assayed by a chemiluminescence assay. The procedure for enzyme reaction was modified and optimized from a described protocol [37]. To minimize the level of the D-serine that contaminates virtually all commercial L-serine reagents, L-serine (Sigma) was catabolized with porcine kidney D-amino acid oxidase (DAO, Calzyme Laboratories) as follows: up to $200 \mathrm{mM} \mathrm{L-ser-}$ ine was combined with $1.5 \mathrm{U} / \mathrm{ml}$ porcine DAO, $3 \mathrm{U} / \mu \mathrm{l}$ catalase (Sigma) and $84 \mu \mathrm{g} / \mathrm{ml}$ flavin adenine dinucleotide (FAD, Calbiochem) in $0.15 \mathrm{M}$ Tris- $\mathrm{HCl}, \mathrm{pH}$ 8.3; the mixture was incubated at $37^{\circ} \mathrm{C}$ overnight, then was heated at $95^{\circ} \mathrm{C}$ for $10 \mathrm{~min}$ to inactivate the enzymes. The supernatant was collected after centrifugation at $14,000 \times \mathrm{g}$ for $10 \mathrm{~min}$. Removal of D-serine was confirmed by a D-serine chemiluminescence assay, which indicated that DAO pretreatment reduced the levels of contaminating D-serine by a factor of 20 -fold.

SR activity assay was performed with $2.5 \mu \mathrm{g}$ recombinant enzyme in the presence of $50 \mathrm{mM}$ phosphate buffer, $\mathrm{pH}$ 8.0, $52 \mathrm{mM} \mathrm{NaCl}, 15 \mu \mathrm{M}$ PLP, $1 \mathrm{mM}$ ATP, 0.2 $\mathrm{mM}$ DTT, $1 \mathrm{mM} \mathrm{MgCl}_{2}$ and $10 \mathrm{mM}$ pretreated L-serine in a final reaction volume of $50 \mu \mathrm{l}$. After the mixture was incubated at $37^{\circ} \mathrm{C}$ for $30 \mathrm{~min}$, the reaction was terminated by boiling for $5 \mathrm{~min}$. Control incubations for the subtraction of background started with enzyme preparations that had been inactivated by boiling.

The D-serine produced during incubation was monitored by a subsequent chemiluminescence assay. Catabolism of D-serine by DAO generates an $\alpha$-keto acid, $\mathrm{NH}_{4}{ }^{+}$, and hydrogen peroxide. The generation of hydrogen peroxide was quantified by the use of peroxidase and luminol, which emits light. A $10-\mu$ l aliquot of sample or D-serine standard was added to $50 \mu$ l of buffer containing $100 \mathrm{mM}$ Tris- $\mathrm{HCl}, \mathrm{pH} 8.8,50 \mathrm{mM} \mathrm{NaCl}, 2$ units/ml horseradish peroxidase (HRP, Sigma), $16 \mu \mathrm{M}$ luminol (Sigma), and $0.8 \mu \mathrm{g} / \mathrm{ml}$ FAD. After a 10- to 20minute delay, required to decrease a nonspecific luminol luminescence, $60 \mu \mathrm{l}$ of $R$. gracilis DAO $(0.033 \mathrm{U} / \mathrm{ml}$, recombinant; courtesy of L. Pollegioni, U. Insubria, Varese, Italy) was added. A Veritas Microplate Luminometer (Turner Biosystems Inc.) was used to detect luminescence before and after addition of DAO. The value obtained immediately before DAO signal (i.e., after extinction of the nonspecific luminescence) was subtracted from what obtained after DAO, and this remainder was used to calibrate and calculate the D-serine content. $K_{M}$ and $V_{\text {max }}$ of SR reactions were calculated from nonlinear regressions using Graphpad Prism software.

\section{Gel-filtration analysis of recombinant SR}

Aliquots of $50 \mu \mathrm{l}$ of $\sim 5 \mathrm{mg} / \mathrm{ml}$ of recombinant SR were loaded onto a Superdex HR200 gel-filtration column (GE) equilibrated with one of two buffers: 1) $50 \mathrm{mM}$ phosphate buffer, $\mathrm{pH} 8.0,52 \mathrm{mM} \mathrm{NaCl}$; or 2) $50 \mathrm{mM}$ Tris- $\mathrm{HCl}, \mathrm{pH}$ 8.0, $150 \mathrm{mM} \mathrm{NaCl}$. Protein was detected by measuring absorption at $280 \mathrm{~nm}$. The flow rate was kept at $0.5 \mathrm{ml} / \mathrm{min}$. The column void volume was determined with dextran blue. The column was calibrated with proteins from a preparation of gel-filtration standards (Sigma), including cytochrome c (12.4 kDa), carbonic anhydrase $(29 \mathrm{kDa})$, bovine serum albumin (66 $\mathrm{kDa})$, alcohol dehydrogenase (150 kDa), and $\beta$-amylase $(200 \mathrm{kDa})$. The calibration curve was obtained by plotting the $\mathrm{V}_{\mathrm{e}} / \mathrm{V}_{\mathrm{o}}$ ratio against the $\log$ of the molecular weight, where $V_{e}$ is the elution volume of the protein and $V_{o}$ is the void volume of the column.

\section{Protein cross-linking experiments}

Recombinant SR $(12.5 \mu \mathrm{M})$ was incubated with various concentrations of protein cross-linker $\mathrm{BS}^{3}$ (Pierce) in cross-linking buffer $[50 \mathrm{mM}$ borate buffer, $\mathrm{pH} 8.0$ with $0.5 \%$ Triton X-100 (Sigma), 2 mM EDTA, $150 \mathrm{mM}$ $\mathrm{NaCl}$, and $0.2 \mathrm{mM}$ phenylmethylsulfonyl fluoride (PMSF)] on ice for 2 hours. The reactions were quenched by adding $30 \mathrm{mM}$ Tris- $\mathrm{HCl}, \mathrm{pH}$ 7.5. The formation of cross-linked SR protein was analyzed with $10 \%$ SDS-PAGE. The gels were stained with Coomassie 
blue. Protein samples from astrocyte cytosol were also cross-linked; lysates were extracted in cross-linking buffer on ice and cleared by centrifugation at $14,000 \mathrm{~g}$ for 10 minutes at $4^{\circ} \mathrm{C}$. Supernatants $(0.5 \mu \mathrm{g} / \mu \mathrm{l})$ were incubated with various concentrations of protein cross-linker $\mathrm{BS}^{3}$ in cross-linking buffer on ice for $2 \mathrm{~h}$. The reactions were quenched by adding $30 \mathrm{mM}$ Tris- $\mathrm{HCl}, \mathrm{pH}$ 7.5. The formation of cross-linked SR protein was analyzed by western blot assay with anti-SR antibody (BD Biosciences).

\section{Cell culture}

Primary mouse glial cultures were established from cerebral cortex of C57BL/6 mice essentially as described [26]. When primary cultures reached confluency (1-2 weeks), flasks were shaken overnight at $200 \mathrm{rpm}$ at $37^{\circ}$ C. The supernatant containing microglia was removed and fresh medium was added to the flasks, which were incubated for another 5-7 days. This procedure was repeated three to four times after which cells were trypsinized and resuspended in astrocyte medium comprising minimal essential medium (MEM), 10\% fetal bovine serum (FBS), and $0.1 \mathrm{mM}$ L-leucine methyl ester (LLME, Sigma-Aldrich) to eliminate any remaining microglia. Astrocytes were treated with L-LME for two weeks and were subcultured for experiments by trypsinization.

\section{Western blot analysis of SR}

Amounts of recombinant SR or cell extracts equilibrated for protein content were resolved by $10 \%$ SDS-PAGE. Protein was electrophoretically transferred at $100 \mathrm{~V}$ for $1.5 \mathrm{~h}$ onto nitrocellulose membranes, which were then blocked for $1 \mathrm{~h}$ at room temperature with $0.2 \%$ I-Block (Applied Biosystems). A monoclonal antibody generated against mouse SR (BD Biosciences) was diluted 1:500 in I-Block and applied overnight at $4{ }^{\circ} \mathrm{C}$. The blots were then developed with one of the following two methods: 1) for chemiluminescence detection, the membranes were incubated with alkaline phosphatase-conjugated goat anti-mouse antibody (1:2000) and then developed with the Western-Light detection system (Applied Biosystems); 2) for colorimetric detection, the membranes were incubated with alkaline phosphatase-conjugated rabbit anti-mouse antibody at 1:400, and then developed with BCIP/NBT kit (Vector Laboratories).

\section{Statistical analysis}

Data are expressed as mean \pm standard deviation. Data were analyzed using one-way ANOVA followed by post hoc comparisons. A $p$-value $\leq 0.05$ was considered statistically significant.

\section{Acknowledgements and funding}

This work was supported by the National Institute on Aging (USA) [P01AG012411].

\section{Author details}

'Department of Geriatrics, University of Arkansas for Medical Sciences, Little Rock AR 72205, USA. ${ }^{2}$ Department of Neurobiology \& Developmental Sciences, University of Arkansas for Medical Sciences, Little Rock AR 72205, USA. ${ }^{3}$ Geriatric Research Education and Clinical Center, Central Arkansas Veterans Healthcare System, Little Rock AR 72205, USA.

\section{Authors' contributions}

WW carried out all the technical aspects of this study, including cloning of human SR, construction of the expression vector, purification, and assay of SR activity. She also drafted the manuscript. SWB initiated the study, participated in its design and coordination, and completed the final revisions of the manuscript. All authors read and approved the final manuscript.

\section{Authors' information}

WW performed these studies in partial satisfaction of her dissertation requirements for a Ph.D. in the Dept. Neurobiol. \& Dev. Sci. at Univ. Arkansas Med. Sci.; she is currently a postdoctoral scholar in the Dept. of Geriatrics. She previously obtained a B.S. in biochemistry and an M.S. in molecular immunology from Lanzhou Univ. in Gansu, P.R. China, where she received three academic scholarships. SWB obtained a Ph.D. in cell biology from Vanderbilt Univ. and completed postdoctoral training at the Sanders-Brown Center on Aging at Univ. Kentucky. He is currently a Professor in the Dept. of Geriatrics and in the Dept. of Neurobiol. \& Dev. Sci. at Univ. Arkansas Med. Sci.; he is also a Research Health Scientist in the Geriatric Research Education and Clinical Center at the Central Arkansas Veterans Healthcare System. He has served as president of the Arkansas Chapter of the Society for Neuroscience and as a member of the Society for Neuroscience's Committee for Animals in Research; he is currently a member of Council for the American Society for Neurochemistry. He has served on five NIH study sections and special emphasis panels and currently sits on the editorial boards for Current Alzheimer Research, Journal of Neurochemistry, Journal of Neuroinflammation, Journal of Neuroscience Research, Neurobiology of Aging.

Received: 15 July 2011 Accepted: 8 December 2011

Published: 8 December 2011

\section{References}

1. Hashimoto A, Nishikawa T, Hayashi T, Fujii N, Harada K, Oka T, Takahashi K: The presence of free D-serine in rat brain. FEBS Lett 1992, 296:33-36.

2. Wolosker H, Sheth KN, Takahashi M, Mothet JP, Brady RO Jr, Ferris CD, Snyder SH: Purification of serine racemase: biosynthesis of the neuromodulator D-serine. Proc Natl Acad Sci USA 1999, 96:721-725.

3. Schell MJ, Brady RO Jr, Molliver ME, Snyder SH: D-serine as a neuromodulator: regional and developmental localizations in rat brain glia resemble NMDA receptors. J Neurosci 1997, 17:1604-1615.

4. Schell MJ, Molliver ME, Snyder SH: D-serine, an endogenous synaptic modulator: localization to astrocytes and glutamate-stimulated release. Proc Natl Acad Sci USA 1995, 92:3948-3952.

5. Mothet JP, Parent AT, Wolosker H, Brady RO Jr, Linden DJ, Ferris CD, Rogawski MA, Snyder SH: D-serine is an endogenous ligand for the glycine site of the N-methyl-D- aspartate receptor. Proc Natl Acad Sci USA 2000, 97:4926-4931.

6. Stevens ER, Esguerra M, Kim PM, Newman EA, Snyder SH, Zahs KR, Miller RF: $D$-serine and serine racemase are present in the vertebrate retina and contribute to the physiological activation of NMDA receptors. Proc Natl Acad Sci USA 2003, 100:6789-6794.

7. Labrie V, Fukumura R, Rastogi A, Fick LJ, Wang W, Boutros PC, Kennedy JL, Semeralul MO, Lee FH, Baker GB, et al: Serine racemase is associated with schizophrenia susceptibility in humans and in a mouse model. Hum Mol Genet 2009, 18:3227-3243.

8. Inoue R, Hashimoto K, Harai T, Mori H: NMDA- and beta-amyloid1-42induced neurotoxicity is attenuated in serine racemase knock-out mice. J Neurosci 2008, 28:14486-14491. 
9. Gaspar PA, Bustamante ML, Silva H, Aboitiz F: Molecular mechanisms underlying glutamatergic dysfunction in schizophrenia: therapeutic implications. J Neurochem 2009, 111:891-900.

10. Labrie $V$, Roder JC: The involvement of the NMDA receptor D-serine/ glycine site in the pathophysiology and treatment of schizophrenia. Neurosci Biobehav Rev 2010, 34:351-372.

11. Turpin FR, Potier B, Dulong JR, Sinet PM, Alliot J, Oliet SH, Dutar P, Epelbaum J, Mothet JP, Billard JM: Reduced serine racemase expression contributes to age-related deficits in hippocampal cognitive function. Neurobiol Aging 2009, 32:1495-1504.

12. Sasabe J, Chiba T, Yamada M, Okamoto K, Nishimoto I, Matsuoka M, Aiso S: $D$-serine is a key determinant of glutamate toxicity in amyotrophic lateral sclerosis. Embo J 2007, 26:4149-4159.

13. Neidle A, Dunlop DS: Allosteric regulation of mouse brain serine racemase. Neurochem Res 2002, 27:1719-1724

14. De Miranda J, Santoro A, Engelender S, Wolosker H: Human serine racemase: molecular cloning, genomic organization and functional analysis. Gene 2000, 256:183-188.

15. Cook SP, Galve-Roperh I, Martinez Del Pozo A, Rodriguez-Crespo I: Direct calcium binding results in activation of brain Serine Racemase. J Biol Chem 2002, 20:27782-27792.

16. Shoji K, Mariotto S, Ciampa AR, Suzuki H: Regulation of serine racemase activity by $\mathrm{D}$-serine and nitric oxide in human glioblastoma cells. Neurosci Lett 2006, 392:75-78

17. Shoji K, Mariotto S, Ciampa AR, Suzuki H: Mutual regulation between serine and nitric oxide metabolism in human glioblastoma cells. Neurosci Lett 2006, 394:163-167.

18. Mustafa AK, Kumar M, Selvakumar B, Ho GP, Ehmsen JT, Barrow RK, Amzel LM, Snyder SH: Nitric oxide S-nitrosylates serine racemase, mediating feedback inhibition of D-serine formation. Proc Natl Acad Sci USA 2007, 104:2950-2955.

19. Dunlop DS, Neidle A: Regulation of serine racemase activity by amino acids. Brain Res Mol Brain Res 2005, 133:208-214.

20. Strisovsky K, Jiraskova J, Mikulova A, Rulisek L, Konvalinka J: Dual substrate and reaction specificity in mouse serine racemase: identification of highaffinity dicarboxylate substrate and inhibitors and analysis of the betaeliminase activity. Biochemistry 2005, 44:13091-13100.

21. Mustafa AK, van Rossum DB, Patterson RL, Maag D, Ehmsen JT, Gazi SK, Chakraborty A, Barrow RK, Amzel LM, Snyder SH: Glutamatergic regulation of serine racemase via reversal of PIP2 inhibition. Proc Natl Acad Sci USA 2009, 106:2921-2926.

22. Kim PM, Aizawa H, Kim PS, Huang AS, Wickramasinghe SR, Kashani AH, Barrow RK, Huganir RL, Ghosh A, Snyder SH: Serine racemase: activation by glutamate neurotransmission via glutamate receptor interacting protein and mediation of neuronal migration. Proc Natl Acad Sci USA 2005, 102:2105-2110

23. Baumgart F, Mancheno JM, Rodriguez-Crespo I: Insights into the activation of brain serine racemase by the multi-PDZ domain glutamate receptor interacting protein, divalent cations and ATP. Febs J 2007, 274:4561-4571.

24. Fujii K, Maeda K, Hikida T, Mustafa AK, Balkissoon R, Xia J, Yamada T, Ozeki Y, Kawahara R, Okawa M, et al: Serine racemase binds to PICK1: potential relevance to schizophrenia. Mol Psychiatry 2006, 11:150-157.

25. Hikida T, Mustafa AK, Maeda K, Fujii K, Barrow RK, Saleh M, Huganir RL, Snyder SH, Hashimoto K, Sawa A: Modulation of D-serine levels in brains of mice lacking PICK1. Biol Psychiatry 2008, 63:997-1000.

26. Wu S-Z, Bodles AM, Porter MM, Griffin WST, Basile AS, Barger SW: Induction of serine racemase expression and D-serine release from microglia by amyloid b-peptide. J Neuroinflammation 2004, 1:2-12.

27. Wu S-Z, Barger SW: Serine racemase induction by inflammatory stimuli is dependent on AP-1. Ann N Y Acad Sci 2004, 1035:133-146.

28. Smith MA, Mack V, Ebneth A, Moraes I, Felicetti B, Wood M, Schonfeld D, Mather O, Cesura A, Barker J: The structure of mammalian serine racemase: evidence for conformational changes upon inhibitor binding. J Biol Chem 2010, 285:12873-12881.

29. D'Autreaux B, Toledano MB: ROS as signalling molecules: mechanisms that generate specificity in ROS homeostasis. Nat Rev Mol Cell Biol 2007, 8:813-824.

30. Denu JM, Tanner KG: Specific and reversible inactivation of protein tyrosine phosphatases by hydrogen peroxide: evidence for a sulfenic acid intermediate and implications for redox regulation. Biochemistry 1998, 37:5633-5642.
31. Kettenhofen NJ, Wood MJ: Formation, reactivity, and detection of protein sulfenic acids. Chem Res Toxicol 2010, 23:1633-1646.

32. Spadaro D, Yun BW, Spoel SH, Chu C, Wang YQ, Loake GJ: The redox switch: dynamic regulation of protein function by cysteine modifications. Physiol Plant 2010, 138:360-371.

33. Mieyal JJ, Gallogly MM, Qanungo S, Sabens EA, Shelton MD: Molecular mechanisms and clinical implications of reversible protein Sglutathionylation. Antioxid Redox Signal 2008, 10:1941-1988.

34. Lindahl M, Mata-Cabana A, Kieselbach T: The disulfide proteome and other reactive cysteine proteomes: analysis and functional significance. Antioxid Redox Signal 2011, 14:2581-2642.

35. Wu S, Basile AS, Barger SW: Induction of serine racemase expression and D-serine release from microglia by secreted amyloid precursor protein (sAPP). Curr Alzheimer Res 2007, 4:243-251.

36. Zhang H, Andrekopoulos C, Joseph J, Chandran K, Karoui H, Crow JP, Kalyanaraman B: Bicarbonate-dependent peroxidase activity of human $\mathrm{Cu}, \mathrm{Zn}$-superoxide dismutase induces covalent aggregation of protein: intermediacy of tryptophan-derived oxidation products. J Biol Chem 2003, 278:24078-24089.

37. Wolosker H, Blackshaw S, Snyder SH: Serine racemase: a glial enzyme synthesizing D-serine to regulate glutamate-N-methyl-D-aspartate neurotransmission. Proc Natl Acad Sci USA 1999, 96:13409-13414.

doi:10.1186/1471-2091-12-63

Cite this article as: Wang and Barger: Roles of quaternary structure and cysteine residues in the activity of human serine racemase. BMC Biochemistry 2011 12:63.

\section{Submit your next manuscript to BioMed Central and take full advantage of:}

- Convenient online submission

- Thorough peer review

- No space constraints or color figure charges

- Immediate publication on acceptance

- Inclusion in PubMed, CAS, Scopus and Google Scholar

- Research which is freely available for redistribution

Submit your manuscript at www.biomedcentral.com/submit
C Biomed Central 